\title{
La necesidad de una educación en el perdón en los cuentos infantiles tradicionales:
}

Caperucita Roja y Blancanieves

Anca-Nicoleta Rotila al286523@uji.es 
I. Resumen

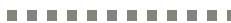

Debido a la gran importancia que tienen los cuentos infantiles en el desarrollo del carácter de los más pequeños, esta investigación tiene como objetivo el análisis de los valores que se enseñan en dos cuentos tradicionales, Caperucita Roja y Blancanieves. Para ello hemos utilizado como metodología, por una parte, el estudio de las dos historias en las versiones de los hermanos Grimm y, por otra parte, se ha recurrido a las investigaciones de autores como Bruno Bettelheim, entre otros.

De esta manera, expondremos ideas como las de familia, respeto, cuidado de los mayores o generosidad en estas narraciones. Además, destacaremos la enseñanza del castigo y la venganza en estos cuentos, así como su influencia en el comportamiento de los futuros adultos, y la necesidad de una educación en el perdón.
\end{abstract}

Palabras clave: cuentos, valores, niños y niñas, castigo, perdón.

\title{
II. Introducción
}

Cuando son pequeños, los niños y las niñas adquieren su bagaje cultural y, por tanto, su forma de entender de la vida. Por una parte, lo hacen a través del impacto que los padres causan en su carácter $y$, por otra parte, a través de la literatura infantil.

Por esta razón, el objetivo de este trabajo es el de analizar los valores que se enseñan en dos de los cuentos tradicionales por excelencia, Caperucita Roja y Blancanieves, para que, ulteriormente, podamos extraer conclusiones y proponer alternativas.

De esta manera, la estructura del siguiente trabajo empieza con el análisis de los valores que se enseñan mediante los cuentos de Caperucita Roja y Blancanieves. Posteriormente, nos adentramos en la profundidad de este estudio previo en el apartado "Resultado del análisis de los valores en Caperucita Roja y Blancanieves». Para terminar, expondremos las conclusiones y razonamientos finales.

\subsection{Caperucita Roja}

Al ser un cuento tradicional y muchas veces reinterpretado, Caperucita Roja es conocida como tal por primera vez gracias al autor francés Charles Perrault. Ya que esta versión no es muy conocida hoy en día, nos centraremos en la interpretación del mismo cuento de los hermanos Grimm.

La historia de Caperucita es ampliamente conocida: se trata de una niña cuya madre envía a visitar a su abuela enferma y en el camino se encuentra al lobo que, por su culpa, logra comerse a la abuela. Como la mayoría de los cuentos tradicionales, este también 
contiene cierta violencia que apenas se aprecia en otros relatos más recientes. Sin embargo, aparte de la violencia, como en todos los cuentos, en Caperucita Roja podemos observar ciertos valores que influyen en la mentalidad infantil.

Uno de los valores que más resaltan en este cuento es el de la familia. Aunque en ningún momento de la historia se menciona al padre de Caperucita, la niña ama a su familia, compuesta por la madre y la abuela. No obstante, cabe detenerse en este aspecto para resaltar el hecho de que la idea de familia transmitida por el cuento no es lo que se entiende por tradicional, compuesta por la madre, el padre y los hijos, sino que nos enseña una familia compuesta por la madre y su hija. Además, la preocupación de Caperucita por su abuela enferma educa a los niños en el cuidado de los mayores o de los abuelos. Asimismo, si nos centramos en la relación de la niña con su abuela, podemos hablar también de valores como la solidaridad o el respeto.

Conforme avanza la historia, puede que el valor más destacado de la trama es el de aprender a no confiar en los extraños. Hay que mencionar que, en un principio, esta historia tenía una connotación sexual muy acusada, ya que, en la versión del autor Perrault el lobo seduce a la niña con unas intenciones sexuales. Esta interpretación del siglo XV trata de enseñar a las niñas y adolescentes a no confiar en los hombres que intentan seducirlas. La versión actualizada, cuyos valores estamos analizando, tiene como finalidad enseñar a los más pequeños a no irse con extraños, y sobre todo, a no hablar con estos. Así, debido a que Caperucita le reveló la dirección de la abuelita al lobo, este pudo llegar primero y comérsela.

Otro valor relevante de nuestra historia es el de no desobedecer nunca a los padres. Recordemos que, al salir de casa, la madre de Caperucita le dijo que tuviera cuidado al pasar por el bosque y que nunca se apartase del camino; claramente, la niña no obedeció, puesto que habla con el lobo y se queda a recoger flores allí donde este le enseñó (Bettelheim, 1999: 176-191).

Al final del cuento, llegamos al momento en el que el cazador salva a la niña y a su abuela cortando la barriga del lobo. Sin embargo, el cuento no finaliza aquí, sino que a Caperucita se le ocurre que pueden ponerle piedras en la barriga y coserla de nuevo. Por consiguiente, trasluce el deseo de venganza en la niña, más allá del castigo que el lobo ya recibe por comerse a las dos féminas. Retomaremos este aspecto en las conclusiones de nuestros análisis.

\subsection{Blancanieves}

El cuento de Blancanieves, aunque en su versión original destaca por el papel de la propia protagonista, en la versión de los hermanos Grimm también adquieren gran importancia los enanitos, de forma 
que el cuento pasa a conocerse como Blancanieves y los siete enanitos.

Siguiendo el mismo patrón que en el análisis del cuento anterior, el primer valor que se destaca en esta historia es la envidia o, mejor dicho, el papel destructivo de la envidia. La madrastra de Blancanieves está celosa o tiene envidia de la niña por ser más guapa que ella. Este hecho puede servir de ejemplo positivo para los más pequeños, al enseñarles que uno se debe querer a sí mismo tal y como es, y que tener envidia solo acaba provocando efectos negativos.

Al igual que en el ejemplo anterior, conviene hablar del papel de la familia que enseña este cuento. Se trata de una familia monoparental, similar a la de Caperucita Roja; sin embargo, en este caso Blancanieves vive con su madrastra después de la muerte de su padre. A modo de inciso, consideramos que mostrar ejemplos de familias diferentes al modelo tradicional impuesto por la religión tiene un gran valor educativo.

También podemos ver que la solidaridad está muy presente, más aún si cabe en el viaje que Blancanieves ha de realizar hasta lograr su final feliz. Conviene recordar que la madrastra encarga a un cazador que mate a la niña. No obstante, este la deja escapar y entrega a la reina los pulmones y el hígado de un jabalí. Se trata, pues, de un gran ejemplo de solidaridad para los niños y las niñas, así como de una anécdota que enseña que se debe ayudar a los demás si surge la oportunidad.

Es de destacar también la generosidad con la que es recibida Blancanieves por parte de los enanitos; así como la manera en la que lo comparten todo con ella y el compañerismo que encuentra entre los propios enanitos: se ayudan, trabajan juntos, viven juntos, etc. Aun así, hay que mencionar el hecho de que Blancanieves, durante su estancia en la casa de los enanitos, se dedica a los trabajos del hogar. Encontramos aquí un ejemplo del currículum oculto que subyace a los cuentos tradicionales y que construye los roles de género, entre otros aspectos.

Al igual que en el cuento de Caperucita Roja, Blancanieves es una niña inocente que decide abrirle la puerta a la reina disfrazada, aunque los enanitos le habían dicho que no abriera la puerta a nadie. Una vez más vemos un ejemplo de las consecuencias que tiene la desobediencia hacia los padres o mayores, y de qué puede pasar cuando hablamos con extraños.

Como sucede en la mayoría de los cuentos de hadas, este acaba con la boda de Blancanieves y el príncipe, después de que este la devolviese a la vida con su beso. En contraste, la madrastra de Blancanieves fue condenada a calzar unos zapatos de hierro calentados al rojo vivo, con los que tendría que bailar hasta morir 
(Bettelheim, 1999: 207-222). Una vez más encontramos el tema del castigo, en el que profundizaremos en el siguiente apartado.

\section{Resultado del análisis de los valores en Caperucita Roja y Blancanieves}

Antes de entrar plenamente en los resultados de nuestra investigación, cabe recordar la importancia que tienen los cuentos en la vida de los infantes. Habida cuenta de la trascendencia de estas historias en el carácter de los niños y las niñas, los cuentos infantiles deben dar mucha importancia a las inquietudes de los más pequeños, darles soluciones, abordar sus problemas con seriedad $y$, al mismo tiempo, acrecentar su confianza en ellos mismos y en sus futuros (Bettelheim, 1999: 11). De esta manera, podemos apreciar que cada uno de nosotros tiene todo un bagaje de conocimientos extraídos de los llamados cuentos populares de hadas. Son historias que poco tienen que ver con la sociedad moderna, pero que ofrecen una educación moral basada en lo experiencial, así como en conceptos abstractos. "En este sentido, los cuentos de hadas tienen un valor inestimable, puesto que ofrecen a la imaginación del niño nuevas dimensiones a las que le sería imposible llegar por sí solo» (Bettelheim, 1999: 13). Asimismo, en los cuento de hadas se plantean problemas de una forma concisa, para que el niño o la niña puedan abordarla de una manera sencilla. De esta forma, se evitan las situaciones complejas, al apoyarse en personajes típicos y no únicos (Bettelheim, 1999: 14).

Al igual que en los dos ejemplos que analizamos anteriormente, Caperucita Roja y Blancanieves, un hecho destacable es que en los cuentos los personajes no son buenos y malos al mismo tiempo, como en la vida real. Cada personaje tiene su carácter bien definido y a lo largo del cuento no lo cambia en ningún momento. Así, los niños se identifican con el héroe, de tal manera que, cuantas más acciones llenas de honradez realiza un personaje, más fácil le será al infante identificarse con este. Por tanto, vemos que en la niñez no se preguntan si quieren ser buenos o malos sino que la cuestión es más bien a quién quieren parecerse. Es un acto mimético típico de la infancia (Bettelheim, 1999: 15). Además, en la gran mayoría de los cuentos tradicionales de hadas, el personaje malvado consigue el puesto del héroe por un periodo limitado. Para ejemplificar esto podemos pensar en el lobo de Caperucita Roja o la malvada madre de Blancanieves.

Sin embargo, como ya anticipamos en los dos apartados anteriores, queremos detenernos en el castigo. En todos los cuentos infantiles tradicionales, el personaje malo o negativo es castigado al acabar el cuento, lo que no podemos decir que constituya un buen ejemplo o experiencia en la educación moral del infante. Tal como 
nos explica el autor Bettelheim: "Tanto en los cuentos de hadas como en la vida real, el castigo, o el temor al castigo, sólo evita el crimen de modo relativo» (Bettelheim, 1999: 14-15). Por tanto, entendemos que el castigo aparece en cada uno de los cuentos para enseñarnos que la venganza mediante el crimen no cambiaría nada en el personaje negativo. No obstante, mediante el castigo tampoco se nos muestra una trasformación del carácter considerado como malo o negativo. Es decir, por un lado, se enseña a los niños que cualquier acto malvado o que no cumpla con unas determinadas normas será castigado gravemente. Por otra parte, independientemente del acto, se da máxima importancia al castigo y nunca al perdón.

Continuando con esta idea, si partimos de la gran influencia educativa moral que tienen los cuentos en el carácter infantil, puede deducirse que la conducta dañina o vengativa de la futura persona adulta podría tener sus antecedentes aquí, en los cuentos de hadas. Al igual que estas historias nos influyen en la idea de familia convencional, mediante el príncipe y la princesa, o que cada disputa entre grandes reyes se acaba en una guerra, se contribuye así a la idea de que debemos vengarnos de todo aquello que nos hagan y aplicar un castigo. Puede considerarse que algunas de las conductas que se pueden ver en la sociedad actual tienen parte de su germen en los cuentos tradicionales.

En relación con esta idea, en el sistema educativo actual, encontramos un gran vacío, especialmente en lo relativo al perdón. Aunque en los últimos años se ha puesto cada vez más de moda la educación en valores, este hueco del que hablamos sigue sin ser tratado y se continúan dejando de lado algunas experiencias básicas como el perdón o el arrepentimiento, entre otras. Si nos remitimos al pasado de cada uno, podríamos recordar cómo se trataba el perdón en la educación infantil, cuando la maestra o el maestro nos exigían pedir perdón por morder, pegar o cualquier otro acto similar. A pesar de ello, el perdón no se aborda desde un punto de vista más profundo, como sucede con otros valores como la solidaridad, el respeto o el amor. También parece que el tema del perdón queda relegado a los primeros años y no resurge conforme avanzamos en los años del estudio.

Según los autores María del Rosario González Martín y Juan Luis Fuentes, "el perdón es decisivo en la constitución de una persona sana, o al menos, la decisión constante de otorgarlo o no» (González Martín y Fuentes, 2012: 480). Por tanto, el perdón debería ser una de los temas prioritarios en el currículum educativo. En nuestra sociedad, en la que las emociones suelen considerarse de segundo orden o directamente ningunearse, es preciso recurrir a dinámicas tan profundas como es el perdón, en las que el niño o la niña no retengan una imagen negativa tanto del otro como de sí mismos, así 
como que aprendan a gestionar sus sentimientos de venganza y futura reparación. Sin el perdón, aunque la situación conflictiva se haya detenido, la relación no se puede curar (González Martín y Fuentes, 2012: 482).

Además, aunque el ámbito familiar es reconocido como un lugar ético en el que se deben aprender los valores básicos desde los primeros años de vida, el ámbito educativo, debido a la gran cantidad de relaciones interpersonales y sociales que se establecen en las escuelas, debe involucrarse en la enseñanza del perdón. «Como toda experiencia humana el perdón necesita ser educado y por ello, ni la familia ni la escuela pueden ignorarlo» (González Martín y Fuentes, 2012: 485). Por tanto, toda educación debe enseñar, aparte de la transformación pacífica de conflictos mediante la comunicación, la trasformación sana y constructiva de las personas, la comunidad y la sociedad.

Así, en el proceso educativo el educador debe ejercer de facilitador que ayude al alumnado a abordar de frente la acción negativa que ha recibido, de manera que pueda valorarla sin justificarla o relativizarla. El educador debe partir de la idea del conflicto como algo inherente a la condición humana, y por tanto, imposible de evitar. Aunque un conflicto puede resultar una experiencia negativa, se ha de tratar como una oportunidad de cambio. Como la autora Sonia París Albert (2009: 21) nos dice:

Así, siguiendo a Francisco Muñoz, se considera que el carácter positivo o negativo de los conflictos depende de los medios que son usados para su regulación. En este sentido, el conflicto será negativo si es gestionado con violencia y positivo si es regulado con la práctica de medios pacíficos. En el primero de los casos su carácter negativo será fruto de las consecuencias destructivas que la violencia produce, a diferencia el segundo en el cual será positivo debido al cuidado de las relaciones que se alcanza cuando se actúa de manera pacífica.

Es más, "enfrentarse al mal cometido y sus consecuencias es ocasión de crecimiento personal» (González Martín y Fuentes, 2012: 486).

Si profundizamos en la necesidad de educar en el perdón, podemos hablar de recuperación de la dignidad y de la esperanza. Según nos dice la autora Arendt (1995: 29), el perdón nos aleja de la venganza y "logra dar lugar a un nuevo comienzo allí donde todo parecía haber concluido». Y esto se debe a que, como personas $y$, por tanto, actores, somos capaces de perdonar y arrepentirnos (Hilb, 2015: 46), más aún cuando el perdón y la reconciliación se traducen en trabajo conjunto por un mundo común mejor (Hilb, 2015: 52). 
Si abundamos un poco más en el tema, podemos afirmar que el perdón y la promesa son facultades sin las que la acción no es posible (López, 2011: 269); aquí entendemos por acción:

... ese poder de hacerse parte del mundo espontáneamente; de comenzar procesos originarios como la existencia humana misma. La acción, en estos términos, es una actividad enteramente positiva, pues desvela la posibilidad del comienzo que es inherente al nacimiento, al origen, de la humanidad.

Hannah Arendt nos explica que no podemos retroceder el tiempo para deshacer un mal ya cometido, y tampoco podemos garantizar que ese mal no se volverá a hacer. Pero ante estas imposibilidades, los únicos remedios son el perdón y la promesa (López, 2011: 270). Estamos hablando de un perdón que tiene que ver con el amor, no un amor romántico, sino un amor de amistad que, junto con el perdón, se entiende como el respeto al prójimo (López, 2011: 277). Esto se debe a que, según la autora Arendt «el perdón solo puede darse en la relación directa entre quien perdona y quien es perdonado, ya que el perdón y la promesa realizados en soledad $\mathrm{o}$ aislamiento carecen de realidad $\mathrm{y}$ no tienen otro significado que el de un papel desempeñado ante el yo de uno mismo» (Arendt, 2009: 257). A partir de esta última idea, debemos mostrar nuestro desacuerdo con la autora, al considerar que el perdón es una acción personal liberadora con dos vertientes. Por una parte, uno ha de perdonar a su prójimo; por otra parte (quizá la más importante), uno tiene la posibilidad de liberar su conciencia al perdonar.

En suma, esta propuesta no se inscribe en un marco educativo en el que se deban dar "clases de perdón» o enseñarse este valor de una manera forzada. Consideramos que, al igual que otros muchos valores aprendidos desde la infancia, el perdón se ha de trabajar a través de la literatura, desde los cuentos infantiles.

\section{Conclusiones}

Dada la gran importancia que tienen los cuentos infantiles en el desarrollo del carácter de los niños, hemos empezado por analizar los valores transmiten, mediante dos de los cuentos más conocidos, Caperucita Roja y Blancanieves.

Puesto que la versión inicial de Caperucita Roja del autor Charles Perrault no parece estar muy adaptada a los tiempos actuales y tiene cierta inclinación hacia lo sexual, nuestro análisis se basó en la versión adaptada de los hermanos Grimm. Aunque la violencia es patente, como sucede en casi todos los cuentos de este tipo, en la historia de Caperucita Roja también encontramos valores bien ejemplificados que pueden establecer una base educativa para los 
niños y las niñas. De esta manera, a lo largo del cuento encontramos

enseñanzas como el hecho de no confiar en los extraños y no desobedecer a los padres, así como el respeto y el cuidado de los mayores o los abuelos, o bien una idea de familia muy frecuente en nuestros días.

En cuanto al análisis de los valores y enseñanzas presentes en el cuento de Blancanieves, el tema principal de esta historia es cómo la envidia puede llegar a ser destructiva tanto para uno mismo como para los que le rodean. Así pues, destacamos las enseñanzas de solidaridad, generosidad y ayuda al prójimo cada vez que se tiene la oportunidad. Como similitudes entre los dos cuentos analizados, vemos que en ambos se aborda el tema de la familia monoparental y las repercusiones que pueden tener conductas como hablar con extraños o confiar en ellos.

No obstante, si algo podemos destacar no solo en estas dos historias, sino también en la gran mayoría de los cuentos de hadas, es el castigo o la venganza. Partiendo de la afirmación de que gran parte de nuestro bagaje de conocimientos se adquiere durante la infancia mediante los cuentos infantiles, es fácil deducir que parte de estos conocimientos están determinados también por la idea de castigo. Es más, los niños y las niñas se suelen identificar con el héroe, un héroe que siempre gana mediante la venganza o el castigo del personaje negativo, nunca por medio del perdón. Aunque puede parecer una enseñanza mínima y de importancia cuestionable, al igual que las niñas sueñan desde pequeñas con casarse con su príncipe azul debido a la influencia de los cuentos de hadas, consideramos que la idea del castigo de las historias infantiles desempeña un importante papel en los caracteres que predominan en nuestra sociedad adulta actual.

Muy ligado a este problema está la ausencia del tratamiento del perdón dentro del ámbito educativo. Esta experiencia básica entre personas debería estar presente en la educación de los más pequeños desde una edad temprana. De esta manera, al igual que se da mucha importancia a valores como el respeto o la solidaridad, consideramos necesaria la educación en el perdón.

Por una parte, la libertad individual, aparte de otros pilares fundamentales, también tiene como base el perdón, especialmente cuando hablamos de niños cuyo entorno más próximo son las escuelas, en las que abundan las relaciones sociales y, por tanto, los conflictos. Por otra parte, al perdonar podemos hablar de la recuperación de la dignidad y la esperanza, al confiar en la trasformación positiva del conflicto.

Para finalizar, consideramos que la educación en el perdón es de vital importancia en nuestra sociedad, pero no de una manera forzada, sino, al igual que otros valores y enseñanzas que interiorizamos desde pequeños mediante los cuentos, y que se 
quedan con nosotros para toda la vida, el perdón se ha de aprender a través de la literatura infantil.

\section{Bibliografía}

Arendt, Hannah. 1995. De la historia a la acción. Barcelona: Paidós.

Arendt, Hannah y Manuel Cruz. 2009. La condición humana. Barcelona: Paidós.

Bettelheim, Bruno. 1999. Psicoanálisis de los cuentos de hadas. Barcelona: Crítica.

González Martín, María del Rosario y Juan Luis Fuentes. 2012. "Los límites de las modas educativas y la condición humana. Un hueco de la educación de las grandes experiencias: el perdón». Revista Española de Pedagogía 253: 479-493.

Hilb, Claudia. 2015. "Justicia, reconciliación, perdón», En Lesa humanidad: Argentina y Sudáfrica: reflexiones después del Mal, editado por Claudia Hilb, 53-74. España: Katz.

López, María. 2011. "La reversibilidad del tiempo, el perdón y la promesa en Hannah Arendt». Investigaciones fenomenológicas: Anuario de la Sociedad Española de Fenomenología 3: 265-278.

París Albert, Sonia. 2009. Filosofía de los conflictos. Una teoría para su transformación pacífica. Barcelona: Icaria. 